\title{
ORIGINAL ARTICLE Direct conversion of human fibroblasts to induced serotonergic
} neurons

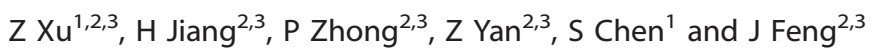

Serotonergic (5HT) neurons exert diverse and widespread functions in the brain. Dysfunction of the serotonergic system gives rise to a variety of mental illnesses including depression, anxiety, obsessive compulsive disorder, autism and eating disorders. Here we show that human primary fibroblasts were directly converted to induced serotonergic (i5HT) neurons by the expression of Ascl1, Foxa2, Lmx1b and FEV. The transdifferentiation was enhanced by p53 knockdown and appropriate culture conditions including hypoxia. The i5HT neurons expressed markers for mature serotonergic neurons, had $\mathrm{Ca}^{2+}$-dependent $5 \mathrm{HT}$ release and selective $5 \mathrm{HT}$ uptake, exhibited spontaneous action potentials and spontaneous excitatory postsynaptic currents. Application of serotonin significantly increased the firing rate of spontaneous action potentials, demonstrating the functional utility of i5HT neurons for studying serotonergic neurotransmission. The availability of human i5HT neurons will be very useful for research and drug discovery on many serotonin-related mental disorders.

Molecular Psychiatry (2016) 21, 62-70; doi:10.1038/mp.2015.101; published online 28 July 2015

\section{INTRODUCTION}

Despite their small numbers $\left(\sim 26000\right.$ in the mouse brain $\left.{ }^{1}\right)$, serotonergic neurons exert diverse and widespread impact on emotion, feeding, aggression, compulsion, sleep and so on. ${ }^{2}$ Dysfunction of the serotonergic system gives rise to a variety of neurological disorders and mental illnesses, including depression, anxiety, obsessive compulsive disorder, autism and eating disorder. ${ }^{2}$ Increasing evidence suggest that individual variations in genes controlling the development and function of serotonergic neurons may lead to a variety of serotonin-related brain disorders. ${ }^{3}$ Thus, it would be very useful to generate patient-specific serotonergic neurons for mechanistic studies of serotonergic dysfunctions and drug discovery research on many serotoninrelated brain diseases. Recent research on transdifferentiation has shown that fibroblasts can be directly converted by different sets of transcription factors to different types of cells. ${ }^{4}$ Ascl1 is a key transcription factor for neurogenesis and early neural differentiation. ${ }^{5}$ It serves as a pioneer factor in the transdifferentiation of fibroblasts to induced neurons. ${ }^{6}$ In Ascl1 knockout mice, there is a profound loss of serotonin, as transcription factors that specify serotonergic neurons such as Pet 1 and $L m \times 1 b$ are not expressed. ${ }^{7}$ FoxA2 establishes the progenitor domains for the precursors of serotonergic neurons in the ventral hindbrain and activates transcription factors required for the terminal differentiation of serotonergic neurons, such as Pet1 and Lmx1b. ${ }^{8}$ Loss of FoxA2 at the precursor stage ablates $50 \%$ of serotonergic neurons in the hindbrain. ${ }^{8}$ Lmx $1 b$ is a critical transcription factor in the terminal differentiation of serotonergic neurons. In Lmx1b-deficient mice, precursors of serotonergic neurons are generated in normal numbers, but they fail to express the battery of genes (Tph2, Sert, Vmat2 and so on) that define a serotonergic neuron., ${ }^{9,10}$ Deletion of Lmx1b specifically in serotonergic neurons results in the loss of these early precursors, confirming the role of $\mathrm{Lm} \times 1 \mathrm{~b}$ in the terminal differentiation of serotonergic neurons. ${ }^{11}$ Pet 1 (FEV in human) expression is restricted to serotonergic neurons. ${ }^{12,13}$ Pet1-deficient precursor cells fail to turn on the expression of serotonergic marker genes, such as Tph2, Aadc, Vmat2, Sert and Maob, resulting in a loss of $70 \%$ serotonergic neurons. ${ }^{14}$

In this study, we found that Dox-inducible lentivirus-mediated expression of Ascl1, FoxA2, Lmx1b and FEV (AFLV) directly converted human fibroblasts to induced serotonergic (i5HT) neurons in 12 days. The transdifferentiation was significantly enhanced by $\mathrm{p} 53$ knockdown and suitable culture conditions including hypoxia. The i5HT neurons expressed appropriate markers for serotonergic neurons and exhibited active serotonergic synaptic transmission. This fast and efficient method of generating i5HT neurons would enable research on patient-specific serotonergic neurons for mechanistic study and drug discovery in many mental illnesses involving serotonergic dysfunction.

\section{MATERIALS AND METHODS}

\section{Materials}

Dorsomorphin dihydrochloride, SB431542, CHIR99021 and Purmorphamine were purchased from Stemgent (Cambridge, MA, USA). Y27632, PD 0332991 isethionate and SU9516 were purchased from Tocris (Bristol, UK). Recombinant human GDNF, BDNF, NGF, bFGF and TGF- $\beta 3$ were purchased from PerproTech (Rocky Hill, NJ, USA). CAMP, Ara-C, Ara-A, ascorbic acid and $\mathrm{N}$-acetyl-L-cysteine were purchased from Sigma (St. Louis, MO, USA). FUWtetO-LoxP-hOCT4, shP53pLKO.1, pMD2.G and psPAX2 were purchased from Addgene (Cambridge, MA, USA). Human Ascl1 (Genebank accession BC031299), Foxa2 (BC011780), Lmx1b (BC113491), FEV (BC023511.2), Nurr1 (CV028069), Lmx1a (BC06635), NeuroD1 (NM_002500), NeuroD2 (NM_006160) and Pitx3(NM_005029) were purchased from Open Biosystems (Pittsburgh, PA, USA) and subcloned by PCR to the EcoRI site on the FUW-tetO-LoxP vector. Human miR-124 (MIMAT0000422) and Nkx2.2

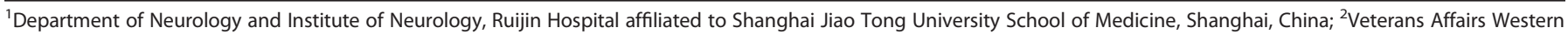

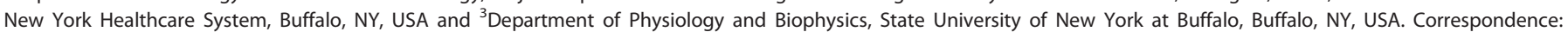

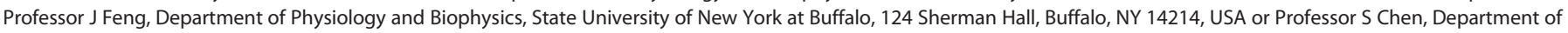
Neurology and Institute of Neurology, Ruijin Hospital affiliated to Shanghai Jiao Tong University School of Medicine, Shanghai 200025, China.

E-mail: jianfeng@buffalo.edu or chen_sd@medmail.com.cn

Received 24 February 2015; revised 8 June 2015; accepted 18 June 2015; published online 28 July 2015 
(NM_002509) were amplified from normal human fibroblast genomic DNA and subcloned to the EcoRI site on the FUW-tetO-LoxP vector. FUW-LoxPM2rtTA was generated by subcloning the BspEl fragment containing the loxP site from FUW-tetO-Loxp-hOCT4 (Addgene) to the BspEl site on the 3 LTR of FUW-M2rtTA (Addgene). All constructs were verified by sequencing.

\section{Derivation of the induced serotonergic neurons}

Primary human fibroblasts MRC5 and CCD-19Lu (both from ATCC, Manassas, VA, USA) and IMR90 (from Coriell, Camden, NJ, USA) were cultured in DMEM containing 10\% FBS and $2 \mathrm{~mm}$ L-glutamine. All cell cultures were done without antibiotics and regularly tested for the absence of mycoplasma by PCR. Lentiviral production and fibroblast infections were performed as described previously. ${ }^{15}$ In brief, lentiviruses were produced by cotransfecting 293FT cells (Invitrogen, Carlsbad, CA, USA) in $10 \mathrm{~cm}$ dishes with $10 \mu \mathrm{g}$ FUW-tetO-LoxP-cDNA (hAscl1, hFoxa2, hLmx1b, hFEV, Lmx1a, Pitx3, NeuroD1, NeuroD2, Nkx2.2, Nurr1 and miRNA-124) or shP53pLKO.1 or $10 \mu \mathrm{g}$ FUW-LoxP-M2rtTA with $2.5 \mu \mathrm{g}$ pMD2.G and $7.5 \mu \mathrm{g}$ psPAX2 using Lipofectamine 2000. Viruses were collected from 16 to $60 \mathrm{~h}$ after transfection and titered for p24 levels using an ELISA kit (ZeptoMetrix Corporation, Buffalo, NY, USA). After the fibroblasts were thawed and passaged once more, they were plated at $5.4 \times 10^{4} \mathrm{~cm}^{-2}$ and infected 1 day later for $16 \mathrm{~h}$ with the indicated combinations of lentiviruses (M2rtTA, hASCL1 and hLmx1b each at MOI 20, hFoxa2, hFEV and hp53shRNA each at MOI 10) in the presence of $8 \mu \mathrm{g} \mathrm{ml}^{-1}$ polybrene. Virus-containing media was removed after $16 \mathrm{~h}$ and replaced with DMEM. After $24 \mathrm{~h}$, the media were changed to neural induction media (DMEM/F12, $1 \times$ N2 supplements, $1 \times$ NEAA, $1 \times$ B27, $10 \mu \mathrm{M}$ ROCK inhibitor Y27632, $1 \mu \mathrm{M}$ PD 0332991, $20 \mathrm{ng} \mathrm{ml}^{-1}$ BDNF and $20 \mathrm{ng} \mathrm{ml}^{-1}$ GDNF) containing $1 \mu \mathrm{g} \mathrm{ml}^{-1}$ doxycycline (stopped at day 7). Dorsomorphin $(0.5 \mu \mathrm{M})$ and $2.5 \mu \mathrm{M}$ SB431542 were added during day 2 to day 7 . The media was changed every other day for the duration of the culture period.

\section{Serotonin release}

i5HT neurons cultured in six-well plates were incubated at $37^{\circ} \mathrm{C}$ in $0.5 \mathrm{ml}$ Hank's balanced salt solution (HBSS) for $30 \mathrm{~min}$, or in $0.5 \mathrm{ml} \mathrm{HBSS}$ for $15 \mathrm{~min}$ and then $56 \mathrm{~mm} \mathrm{KCl}$ was added for another $15 \mathrm{~min}$, or in $0.5 \mathrm{ml} \mathrm{HBSS}$ without $\mathrm{Ca}^{2+}$ and without $\mathrm{Mg}^{2+}$, but with $2 \mathrm{~mm}$ EDTA for $15 \mathrm{~min}$ and then $56 \mathrm{~mm} \mathrm{KCl}$ was added for another $15 \mathrm{~min}$. The HBSS solutions were taken out from the wells and concentrated by Amicon ultra- $0.5 \mathrm{ml} 3 \mathrm{k}$ centrifugal filter units (Millipore, Billerica, MA, USA). The amounts of $5 \mathrm{HT}$ in HBSS solutions were measured by reverse phase HPLC (ESA Model 582 with ESA MD150×3.2 column, at $0.6 \mathrm{ml} \mathrm{min}{ }^{-1}$ flow rate in MD-TM mobile phase) coupled with electrochemical detection (ESA Coulochem III, E1: $-250 \mathrm{mV}, 2 \mu \mathrm{A}$; E2: $350 \mathrm{mV}, 2 \mu \mathrm{A})$. Cells in the wells were lysed in $0.5 \mathrm{~N} \mathrm{NaOH}$ to measure protein levels, which were used to normalize serotonin release.

\section{Serotonin uptake}

i5HT neurons cultured in six-well plates were rinsed with $1 \mathrm{ml}$ prewarmed uptake buffer (10 mm HEPES, $130 \mathrm{~mm} \mathrm{NaCl}, 1.3 \mathrm{~mm} \mathrm{KCl}, 2.2 \mathrm{~mm} \mathrm{CaCl}, 1.2 \mathrm{~mm}$ $\mathrm{MgSO}_{4}, 1.2 \mathrm{~mm} \mathrm{KH} \mathrm{PO}_{4}, 10 \mathrm{~mm}$ glucose, $\mathrm{pH}$ 7.4) three times. Cells were incubated for $5 \mathrm{~min}$ at $37^{\circ} \mathrm{C}$ with $1 \mathrm{ml}$ uptake buffer containing $5 \mu \mathrm{m}$ serotonin without or with $10 \mu \mathrm{m}$ citalopram. After the cells were washed at least three times in uptake buffer, they were lysed in $0.1 \mathrm{~m}$ perchloric acid with $1 \mathrm{~mm}$ EDTA and $0.1 \mathrm{~mm}$ sodium bisulfite. Cleared cell lysates were concentrated by Amicon ultra- $0.5 \mathrm{ml} 3 \mathrm{k}$ centrifugal filter units (Millipore) and analyzed for serotonin on HPLC coupled with electrochemical detection (E1: $-250 \mathrm{mV}, 2 \mu \mathrm{A}$; E2: $350 \mathrm{mV}, 2 \mu \mathrm{A}$ ). The pellets of cellular proteins were dissolved in $0.5 \mathrm{~N} \mathrm{NaOH}$ to measure protein contents, which were used to normalize serotonin uptake. The amount of endogenous serotonin in $\mathrm{i} 5 \mathrm{HT}$ neurons without any treatment was also measured.

\section{Immunocytochemistry}

Cells grown in 12-well plates were fixed in situ with $4 \%$ paraformaldehyde in PBS for 20 min, permeabilized with $0.1 \%$ Triton X-100 in PBS for 20 min at room temperature (RT), blocked in $3 \% \mathrm{BSA}$ in PBS for $60 \mathrm{~min}$ at RT, and then incubated in primary antibody overnight at $4{ }^{\circ} \mathrm{C}$, secondary antibody for $2 \mathrm{~h}$ at RT, DAPI for $20 \mathrm{~min}$ at RT. The sources, catalog numbers and dilutions of the antibodies used in this study are listed in Supplementary Table 2. Fluorescence images were taken on Zeiss Axio Observer Inverted Microscope with lenses corrected for plastic culture plates. The $5 \mathrm{HT}^{+}, \mathrm{Tuj}^{+}$ and $\mathrm{DAPl}^{+}$cells were counted from at least five randomly selected images at $10 \times$ magnification for each condition.
Real time quantitative RT-PCR

Total RNA was extracted using RNeasy Mini kit (QIAGEN, Germantown, MD, USA). First-strand complementary DNA was synthesized with iScript CDNA synthesis kit according to manufacturer's protocol (Bio-Rad 170-8890, Hercules, CA, USA). An equal volume mixture of the products was used as templates for PCR amplification. Reactions were performed in a $25 \mu \mathrm{l}$ volume with iQ SYBR Green Supermix (Bio-Rad) and $200 \mathrm{~nm}$ each of forward and reverse primers shown in Supplementary Table 3 using iCyler and iQ software (Bio-Rad). Each sample was run in duplicate. PCR conditions included an initial denaturation step of $4 \mathrm{~min}$ at $95^{\circ} \mathrm{C}$, followed by 40 cycles of PCR consisting of $30 \mathrm{~s}$ at $95^{\circ} \mathrm{C}, 30 \mathrm{~s}$ at $60^{\circ} \mathrm{C}$ and $30 \mathrm{~s}$ at $72^{\circ} \mathrm{C}$. Average threshold cycle values from the duplicate PCR reactions for a gene of interest were normalized against the average threshold cycle values for GAPDH from the same complementary DNA sample.

\section{Statistical analyses}

The data were expressed as mean \pm s.e.m. Unpaired, two tailed Student's $t$ tests were performed to evaluate whether two groups were significantly different from each other.

\section{RESULTS}

Transdifferentiation of human fibroblasts to induced serotonergic neurons

In an effort to identify transcription factors that can directly convert human fibroblasts to induced serotonergic (i5HT) neurons, we tested a variety of transcription factors involved in the genesis of serotonergic neurons $3,16,17$ or the direct conversion of fibroblasts to induced neurons. ${ }^{4}$ Of these factors (details later), we found that the combined expression of human AFLV generated a large amount of i5HT neurons. Using the protocol in Figure 1a, we transduced human primary fibroblast MRC5 cells with Dox-inducible lentiviruses expressing AFLV and a constitutively active lentivirus for p53 shRNA (AFLVp). After Dox-initiated reprogramming, morphology of the cells changed within days to neuron-like cells (Figures $1 \mathrm{~b}-\mathrm{e}$ ). When cells were stained at day 12 for serotonin (5HT), the neuronal marker $\beta 3$-tubulin (Tuj1), and DAPI, we found that $49.2 \pm 2.1 \%$ of total cells $\left(\mathrm{DAPI}^{+}\right)$were Tuj $1^{+}$ neurons and $24.4 \pm 0.9 \%$ of total cells were $5 \mathrm{HT}^{+}$neurons (Figures $1 \mathrm{f}-\mathrm{h}$ and $\mathrm{n}-\mathrm{q}$ ). Removal of Ascl1 from the transcription factors generated no neuron (Figures $1 \mathrm{i}$ and $\mathrm{n}-\mathrm{q}$ ), demonstrating the requirement for Ascl1 in the transdifferentiation of human fibroblasts to neurons. Removing FoxA2 (Figure $1 \mathrm{j}$ ) or $\mathrm{Lm \times 1b}$ (Figure $1 \mathrm{k}$ ) failed to generate any i5HT neurons (Figure 10), whereas omitting FEV (Figure 1I) produced significantly fewer i5HT neurons (Figure 10) but more Tuj $1^{+}$neurons (Figure 1p). FEV appeared to be somewhat toxic to cells; the number of DAPI ${ }^{+}$cells increased significantly in the absence of FEV (Figure 1q). When we did not include p53 knockdown (Figure $1 \mathrm{~m}$ ), the efficiencies (Figure 1n) and yields (Figures 1o and p) in generating i5HT neurons and Tuj $1^{+}$neurons were significantly reduced. The results suggest that attenuation of p53 significantly improves reprogramming of human fibroblasts to i5HT neurons.

We also tested other transcription factors implicated in the development of serotonergic neurons $s^{3,16,17}$ or transdifferentiation of fibroblasts to induced neurons. ${ }^{4}$ Replacing $L m \times 1 b$ (Figure 2a) with Lmx1a (Figure 2b) significantly decreased the number of $5 \mathrm{HT}^{+}$neurons and slightly reduced the number of $\mathrm{Tuj}^{+}$ cells (Figures $2 \mathrm{i}-\mathrm{I}$ ). In the presence of AFLbVp, the addition of NeuroD1, which has been shown to enhance the conversion of human fibroblasts to induced neurons, ${ }^{18}$ significantly reduced the number of $5 \mathrm{HT}^{+}$cells, but did not significantly affect the number of Tuj $1^{+}$cells or DAPI ${ }^{+}$cells (Figures $2 \mathrm{c}$ and $\mathrm{i}-\mathrm{l}$ ). The addition of NeuroD2, which helps the generation of induced neurons by Ascl1 and Myt $1{ }^{19}{ }^{19}$ abolished the production of $5 \mathrm{HT}^{+}$cells and significantly decreased the number of Tuj $1^{+}$cells and $\mathrm{DAPI}^{+}$ cells (Figures $2 \mathrm{~d}$ and $\mathrm{i}-\mathrm{I}$ ). The addition of miR124, which improves the derivation of human iN cells by Ascl1 and Myt $11,{ }^{19}$ almost 


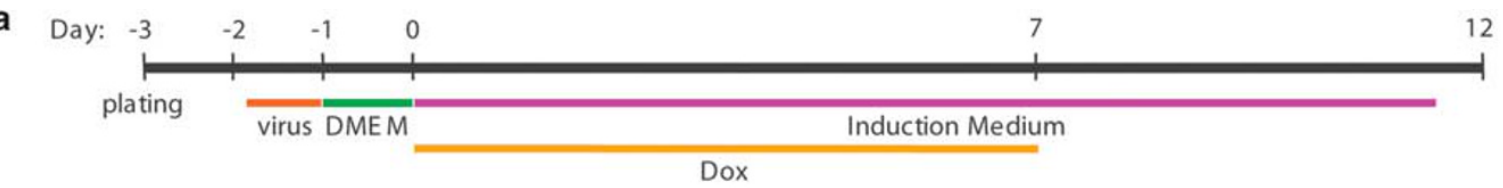
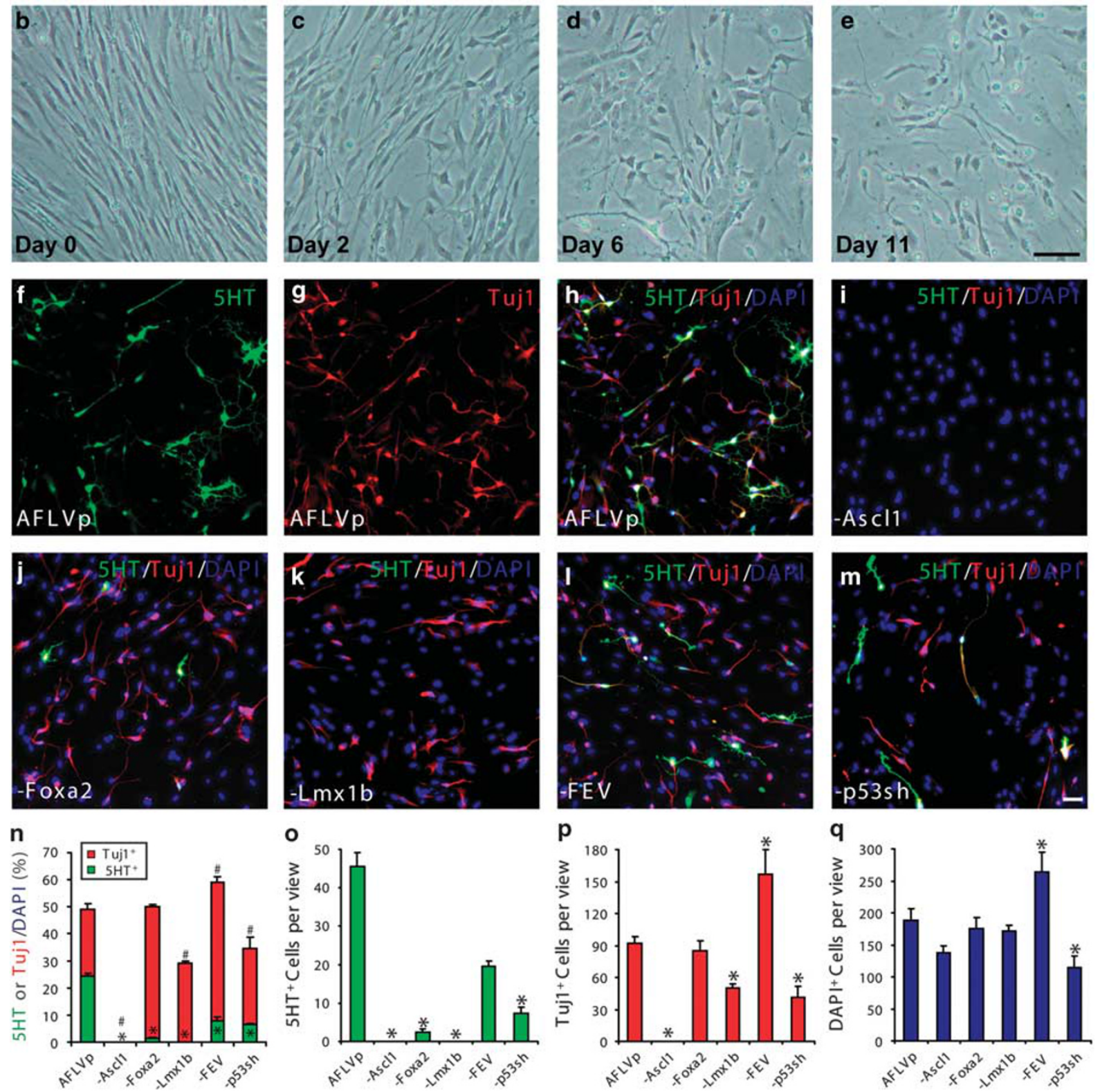

Figure 1. Reprogramming of human fibroblasts to induced serotonergic (i5HT) neurons. (a-h) Using the protocol in (a), MRC5 cells were transduced with lentiviruses expressing Ascl1, Foxa2, Lmx1b, FEV and p53 shRNA (AFLVp). Phase contrast images at days 0 (b), 2 (c), 6 (d) and 11 (e) were shown. Cells at day 12 were stained for 5 HT (f), Tuj 1 (g) and DAPI (h, merged with $\mathbf{f}$ and $\mathbf{g})$. (i-m) MRC5 cells transduced with AFLVp minus Ascl1 (i), Foxa2 (j), Lmx1b (k), FEV (I) or p53 shRNA (m) were stained for 5HT, Tuj1 and DAPI. (n-q) Quantification at day 12 of the percentage of $5 \mathrm{HT}^{+}$neurons or Tuj $1^{+}$neurons among all cells $\left(\mathrm{DAPI}^{+}\right)(\mathbf{n})$ or the average number of $5 \mathrm{HT}^{+}(\mathbf{o}), \mathrm{Tuj}^{+}(\mathbf{p})$ or DAPI ${ }^{+}(\mathbf{q})$ cells per view. ${ }^{*}{ }^{*} P<0.05$, vs $5 \mathrm{HT}^{+}$or Tuj $1^{+}$for AFLVp, respectively, cells from at least five random views in each of the three wells from three independent experiments were counted. Bars $=50 \mu \mathrm{m}$.

completely abrogated the generation of $5 \mathrm{HT}^{+}$cells without significantly affecting the number of Tuj $1^{+}$cells or $\mathrm{DAPl}^{+}$cells

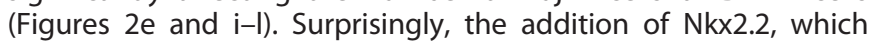
controls the production of $5 \mathrm{HT}$ neurons in posterior rhombomeres, ${ }^{20}$ markedly reduced the number of $5 \mathrm{HT}^{+}$cells, as well as the number of Tuj $1^{+}$and $\mathrm{DAPI}^{+}$cells (Figures $2 \mathrm{f}$ and $\mathrm{i}-\mathrm{l}$ ).
We also tried Nurr1 and Pitx3, which drive the terminal specification of midbrain DA neurons. ${ }^{21}$ Nurr1 significantly reduced the production of $5 \mathrm{HT}^{+}$cells without significantly affecting the number of Tuj $1^{+}$and $\mathrm{DAPI}^{+}$cells (Figures $2 \mathrm{~g}$ and i-I). Pitx3 almost completely abolished the production of $5 \mathrm{HT}^{+}$and Tuj $1^{+}$neurons (Figures $2 \mathrm{~h}-\mathrm{I}$ ). 

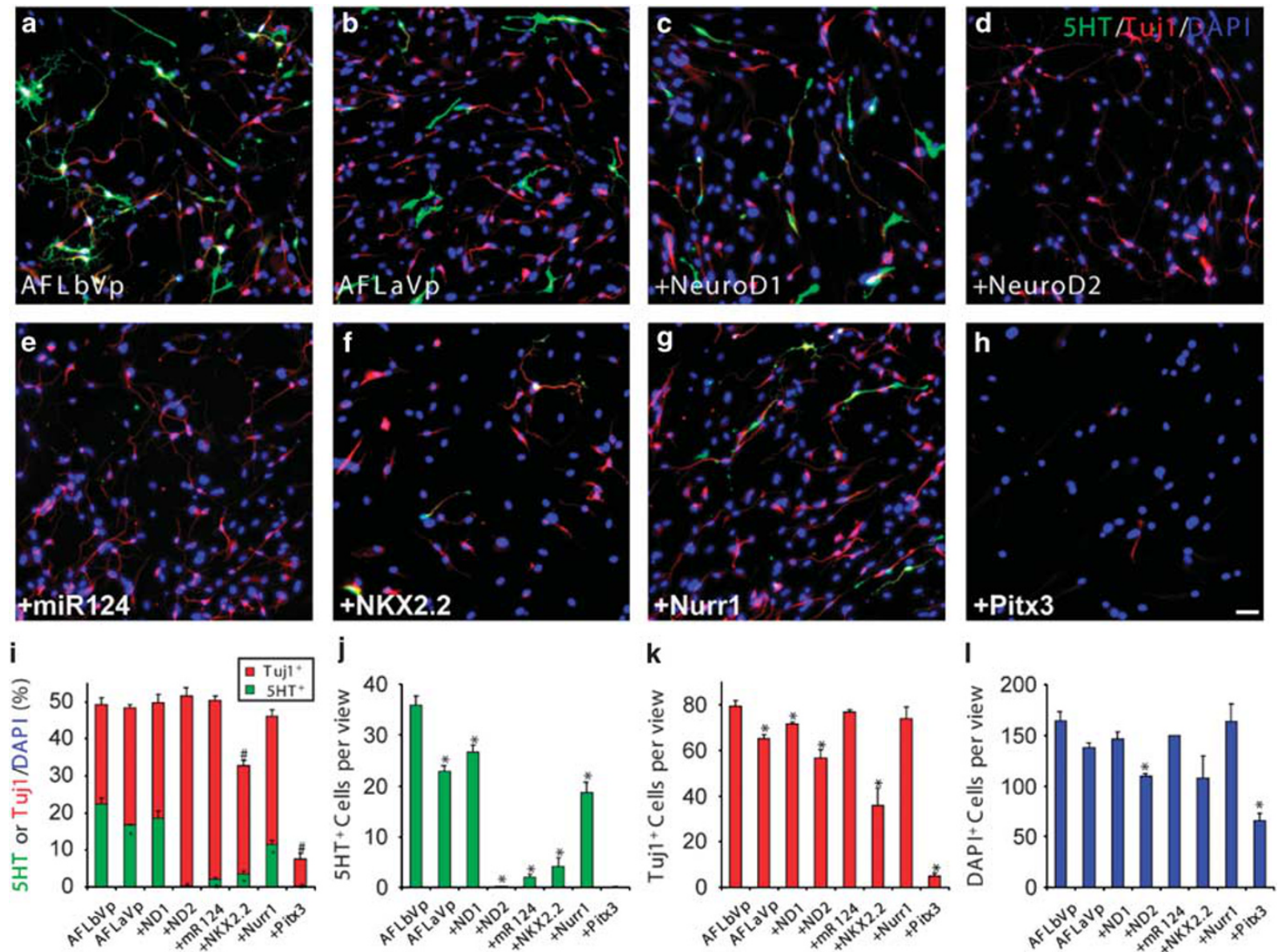

Figure 2. Other transcription factors tested. (a-h) Immunostaining of MRC5 cells reprogrammed with Ascl1, FoxA2, Lmx1b, FEV and p53 shRNA (AFLbVp) (a), Ascl1, FoxA2, Lmx1a, FEV and p53 shRNA (AFLaVp) (b), AFLbVp plus NeuroD1 (c), AFLbVp plus NeuroD2 (d), AFLbVp plus miR124 (e), AFLbVp plus NKX2.2 (f), AFLbVp plus Nurr1 (g) or AFLbVp plus Pitx3 (h). (i-I) Quantification of the percentage of $5 \mathrm{HT}^{+}$neurons or Tuj $1^{+}$neurons among all cells $\left(\mathrm{DAPI}^{+}\right)$(i) or the average number of $5 \mathrm{HT}^{+}(\mathbf{j})$, Tuj $1^{+}(\mathbf{k})$ or DAPI ${ }^{+}(\mathbf{I})$ cells per view. ${ }^{*}{ }^{\#} P<0.05$, vs $5 \mathrm{HT}^{+}$or Tuj $1^{+}$for AFLbVp, respectively, cells from at least five random views in each of the three wells from three independent experiments were counted. Bars $=50 \mu \mathrm{m}$.

Optimization of culture conditions for the generation of i5HT neurons

We tested a variety of small-molecule compounds and neurotrophic factors by adding each of them to the basal media, which was DMEM/F12 plus B27 and N2 (Figure 3a). The addition of the Rock inhibitor Y27632 $(10 \mu \mathrm{m})^{22}$ (Figure 3b), the SMAD inhibitor dorsomorphin (DM, $0.5 \mu \mathrm{M})^{23}$ (Figure 3c) or SB431542 (SB, $\left.5 \mu \mathrm{M}\right)^{24}$ (Figure 3d) or the CDK4/6 inhibitor PD0332991 (PD, $1 \mu \mathrm{m})^{25}$ (Figure 3g) improved both the conversion efficiency and morphology, whereas BDNF (20 $\mathrm{ng} \mathrm{ml}^{-1}$ ) (Figure 3e) and GDNF $\left(20 \mathrm{ng} \mathrm{ml}^{-1}\right.$ ) (Figure 3f) slightly improved the morphology but not the conversion efficiency (Figure $3 \mathrm{j}$ for conversion efficiency and Supplementary Figures S1b-d for conversion yield). Strikingly, induction media with all the six agents (Figure $3 \mathrm{~h}$ ) increased the conversion efficiency from $23.6 \pm 2.6$ to $49.3 \pm 2.1 \%$ for Tuj $1^{+}$ neurons and from $5.7 \pm 0.5$ to $24.7 \pm 1.1 \%$ for $5 \mathrm{HT}^{+}$neurons $(P<0.05)$ (Figure $3 \mathrm{j})$. We substantiated the results by removing each of the six agents from induction media and found that taking away any one of them indeed reduced the conversion efficiency (Supplementary Figure S1e) and yield (Supplementary Figures $\mathrm{S} 1 \mathrm{f}-\mathrm{h})$. Representative images for these conditions are shown in Supplementary Figures S2a-h. Furthermore, we tested many other agents, including the selective GSK3 $\beta$ inhibitor CHIR99021, ${ }^{26}$ the Smoothened agonist Purmorphamine, ${ }^{27}$ the antioxidant vitamin $C$ or NAC, CAMP, bFGF, NGF or TGF $33 .^{15}$ None of them had any favorable effect (Supplementary Figures S1i-I, Supplementary Figures S2i-p). Replacing DMEM in IM with neurobasal markedly reduced the efficiency and yield in the generation of $5 \mathrm{HT}^{+}$neurons (Supplementary Figures S1i-I, Supplementary Figure S2q). A previous study has shown that hypoxia $\left(5 \% \mathrm{O}_{2}\right)$ improves the direct conversion of human fibroblasts to induced neurons. ${ }^{28}$ We found that the conversion of MRC5 cells to i5HT neurons was significantly more efficient at $5 \% \mathrm{O}_{2}$ (Figure $3 \mathrm{~h}$ ) than at $21 \% \mathrm{O}_{2}$ (Figure $3 \mathrm{i}$ ) in induction media (Figure $3 \mathrm{k}$ and Supplementary Figures S1m-p). The selective CDK4/6 inhibitor PD-0332991 significantly reduced the number of $\mathrm{DAPI}^{+}$cells (Supplementary Figure S1d) without affecting the number of $5 \mathrm{HT}^{+}$(Supplementary Figure S1b) or Tuj $1^{+}$neurons (Supplementary Figure S1c), suggesting that it blocks the proliferation of unconverted mitotic cells. We tested other mitotic inhibitors such as the CDK2 inhibitor SU9516, or the DNA synthesis inhibitor AraA or AraC. Replacing PD in induction medium with any of these mitotic inhibitors significantly reduced conversion efficiency (Supplementary Figure S1q) and yield (Supplementary Figures S1r-t and Supplementary Figures S2r-t). After 30 days of culture in induction medium, there was no significant reduction in the number of $5 \mathrm{HT}^{+}$cells (Supplementary Figure S3b), but the number of Tuj $1^{+}$cells (Supplementary Figure $\mathrm{S} 3 \mathrm{c}$ ) and the total number of cells (DAPI ${ }^{+}$, Supplementary Figure 

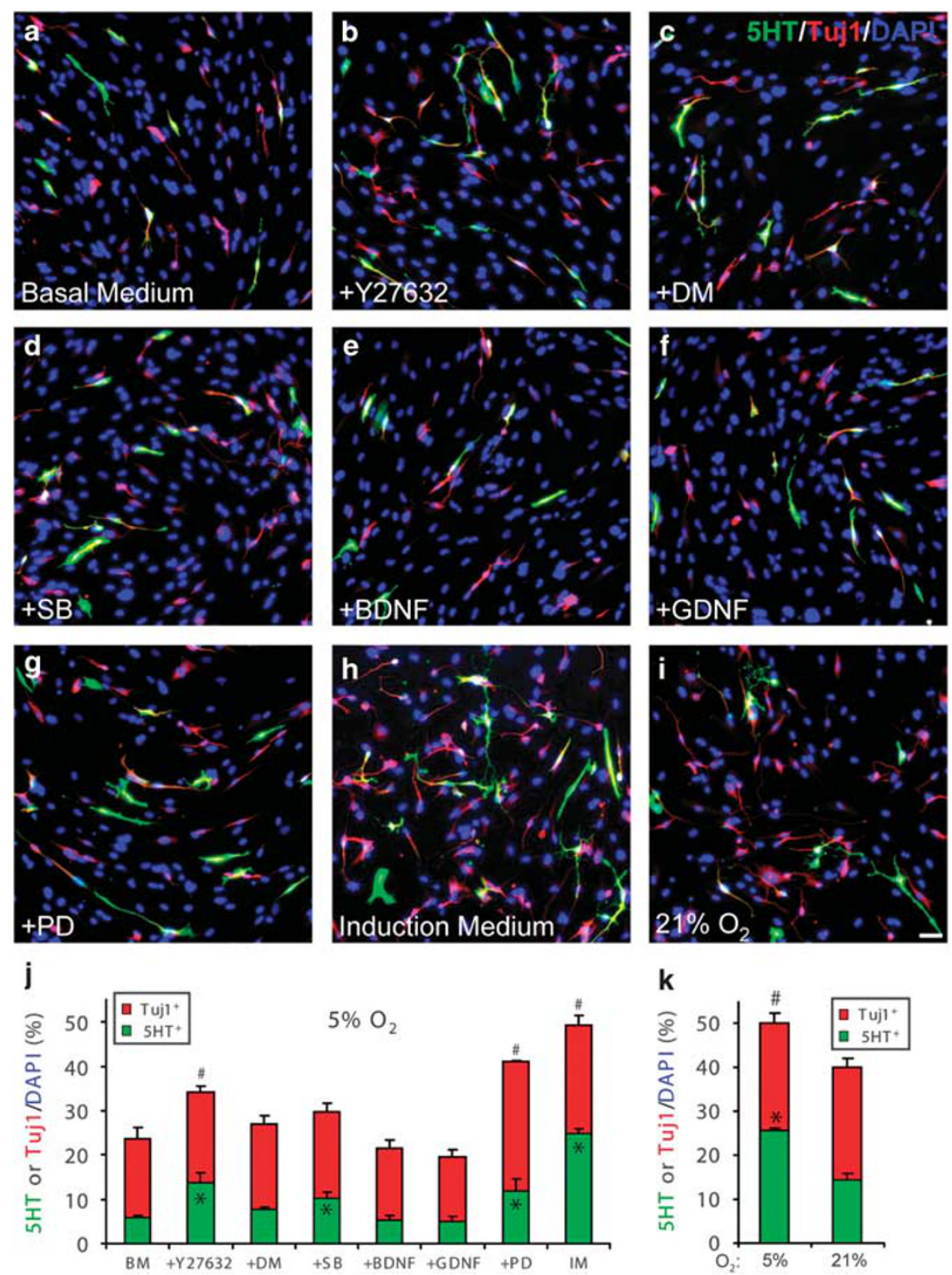

Figure 3. Optimal culture conditions for the conversion of human fibroblasts to induced serotonergic neurons. (a-h) Representative images and quantification (j) of $5 \mathrm{HT}^{+}$or Tuj ${ }^{+}$neurons at day 12 in basal medium (BM, DMEM/F12 plus B27 and N2) (a) plus ROCK inhibitor Y27632 (b), dorsomorphin (DM) (c), SB431542 (SB) (d), brain-derived neurotrophic factor (BDNF) (e), glial cell line-derived neurotrophic factor (GDNF) (f), PD0332991 (PD) (g) or induction media (IM) with all of the above additives (h). (i and $\mathbf{k})$ Representative image (i) and quantification (k) of i5HT neurons converted in $5 \%$ or $21 \% \mathrm{O}_{2} .{ }^{*}{ }^{*} P<0.05, \mathrm{vs} 5 \mathrm{HT}^{+}$or Tuj $1^{+}$for the first bar, cells from at least five random views in each of the three wells from three independent experiments were counted. Bars $=50 \mu \mathrm{m}$.

S3d) decreased significantly, thereby increasing conversion efficiency (Supplementary Figures S3a, e-h).

i5HT neurons expressed appropriate markers for serotonergic neurons

We costained $\mathrm{i} 5 \mathrm{HT}$ neurons with antibodies against serotonin and various serotonergic markers and neuronal markers. As these markers are expressed only in mature serotonergic neurons, we performed the staining when the $\mathrm{i} 5 \mathrm{HT}$ neurons were cultured in vitro for 28 days or longer. As shown in Figure $4 \mathrm{a}$, the i5HT neurons coexpressed serotonin and tryptophan hydroxylase 2 (TPH2, the rate-limiting enzyme for the synthesis of 5HT in the brain). They also coexpressed 5HT with L-aromatic amino-acid decarboxylase (AADC, the enzyme for the second step of $5 \mathrm{HT}$ synthesis) (Figure 4b), vesicular monoamine transporter 2 (VMAT2, for the sequestration of 5HT in synaptic vesicles) (Figure 4c), serotonin transporter (SERT, for the reuptake of released serotonin) (Figure 4d), aldehyde dehydrogenase 1a1 (ALDH1A1, for the degradation of $5 \mathrm{HT}$ ) (Figure 4e), as well as markers for mature neurons such as MAP2 (Figure 4f), NeuN (Figure 4g) and syntaxin 1 (Figure 4h). Separate channels of merged images are shown in Supplementary Figure S4. Real-time quantitative RT-PCR assays showed that endogenous AFLV were strongly induced at day 6 and day 25 (Figures $4 i$ and j). Genes responsible for the synthesis (TPH1, TPH2 and AADC), vesicular sequestration (VMAT2), reuptake (SERT) and degradation (ALDH1A1, MAO-A and MAO-B) of serotonin, as well as serotonin autoreceptors (HTR1a and HTR1b) were all significantly induced (Figures $4 \mathrm{i}$ and $\mathrm{j}$ ). The expression levels of neuronal genes such as MAP2, TUBB3 

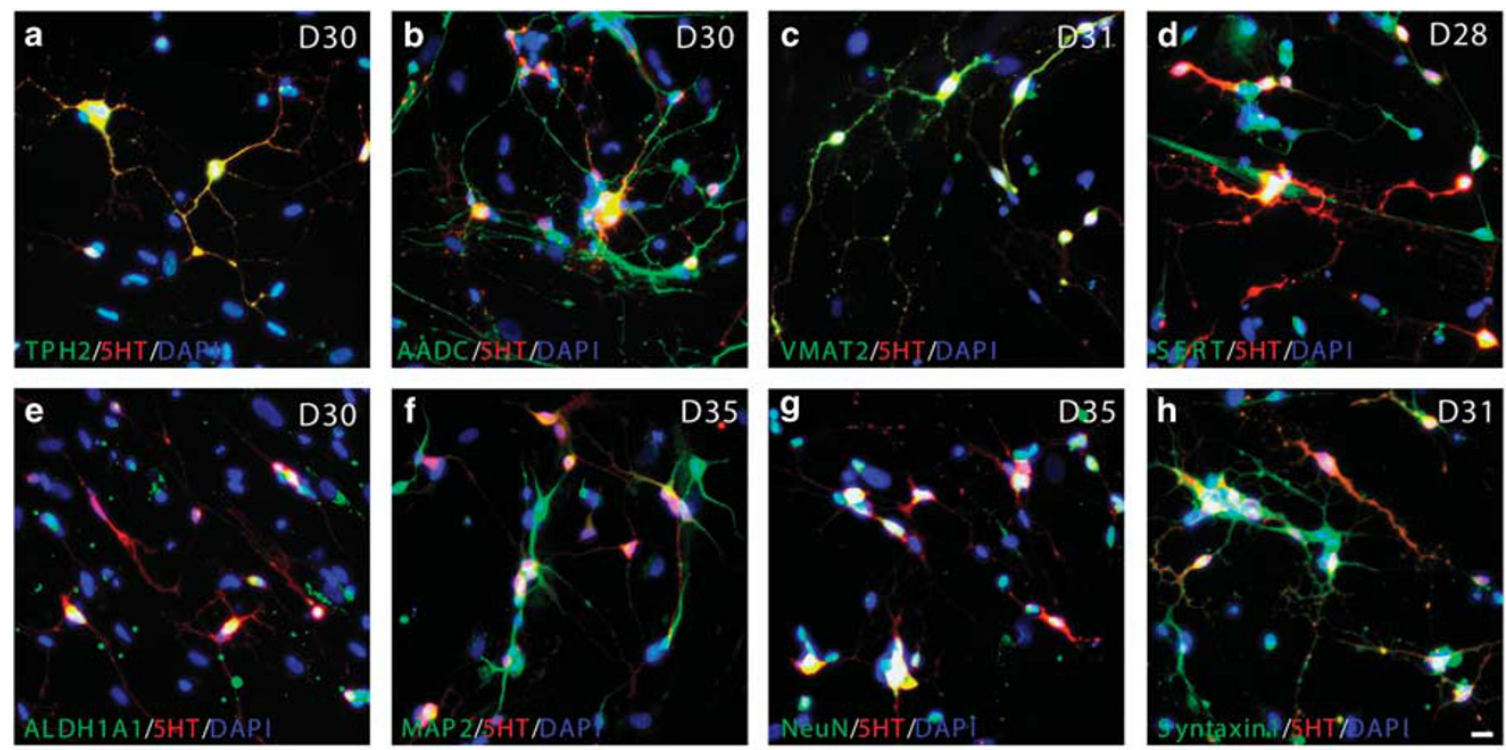

i

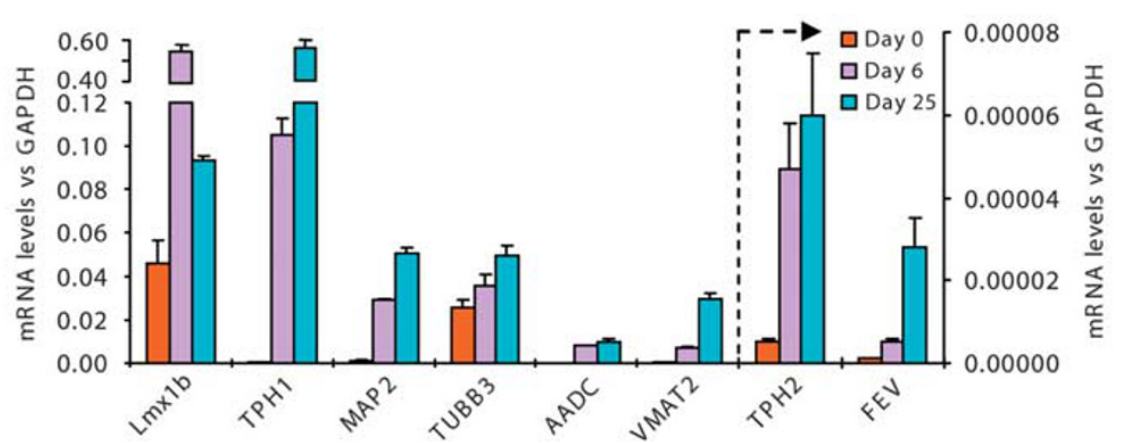

j

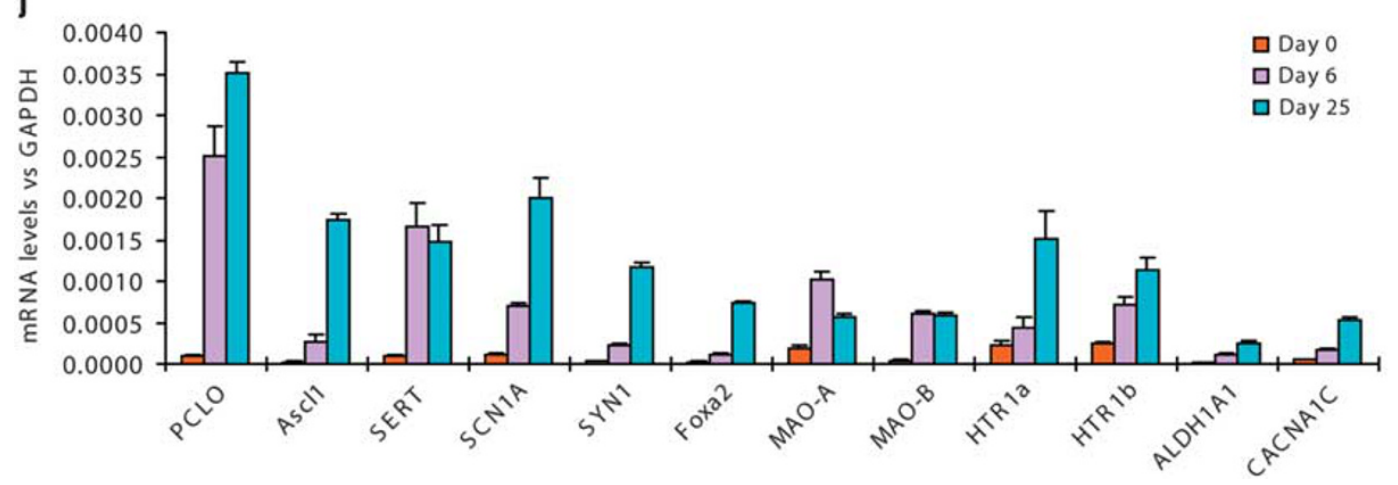

Figure 4. The i5HT neurons express appropriate markers for serotonergic neurons. (a-h) Costaining of i5HT neurons with antibodies against $5 \mathrm{HT}$ and serotonergic markers including AADC (a), ALDH1A1 (b), VMAT2 (c), TPH2 (d), SERT (e), or markers for mature neurons MAP2 (f) and $\operatorname{NeuN}(\mathbf{g})$, or synaptic markers syntaxin-1 (h). Bars, $20 \mu \mathrm{m}$. (i and j) Induction of endogenous genes at different time points after the addition of DOX. Arrow, values were according to the $\mathrm{Y}$ axis on the right. $\mathrm{N}=4$ from three independent experiments.

(33 tubulin), SYN1 (synapsin 1), PCLO (Piccolo Presynaptic Cytomatrix Protein), Cacna1c (CaV1.2 voltage-dependent calcium channel) and Scn1a (NaV1.1 voltage-dependent sodium channel) were significantly increased (Figures $4 \mathrm{i}$ and $\mathrm{j}$ ). These results indicate that the transcription program of the cell was converted to that of serotonergic neurons, consistent with the morphological changes from fibroblasts to neurons (Figures $1 \mathrm{~b}-\mathrm{e}$ ). All five transgenes (AFLVp) were greatly silenced in i5HT neurons (Supplementary Figure S5). This is consistent with the results that DOX was only needed during the first week of transdifferentiation (Figure 1a).
To substantiate our findings, we used the same method to generate i5HT neurons from another line of primary human fetal fibroblasts IMR90 (Supplementary Figures S6a-d) and the primary adult human fibroblasts CCD-19Lu (Supplementary Figures S6e-h). The conversion efficiency and yield of $5 \mathrm{HT}^{+}$and Tuj $1^{+}$neurons were very similar between the fetal fibroblasts MRC5 and IMR90 (Supplementary Figures S6i-I). The conversion efficiency (Supplementary Figure S6i) and yield (Supplementary Figure S6j) of $5 \mathrm{HT}^{+}$neurons from the adult fibroblast CCD-19Lu were much lower, although the generation of Tuj $1^{+}$cells was comparable to the situation in fetal fibroblasts (Supplementary Figures S6i and k). 
a

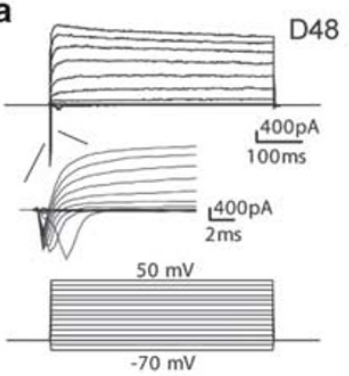

b

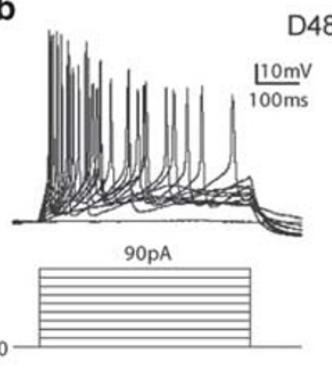

c

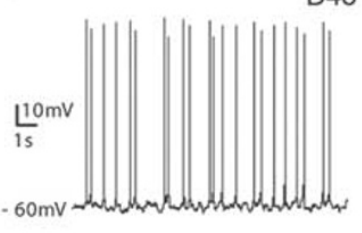

$S$ pontaneous

Action Potentials d

D46

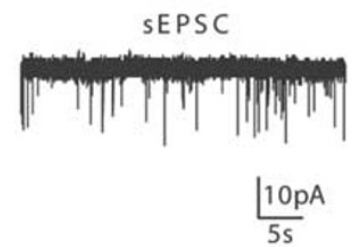

e

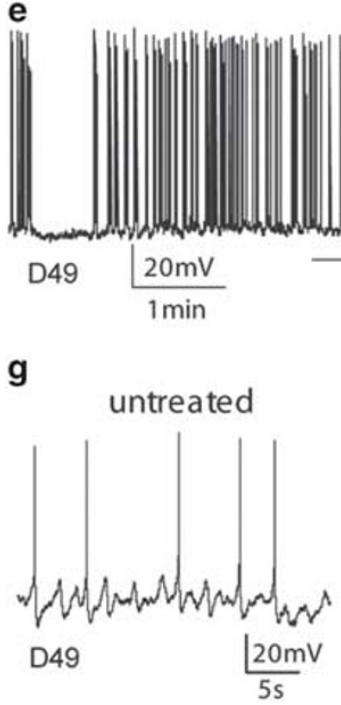

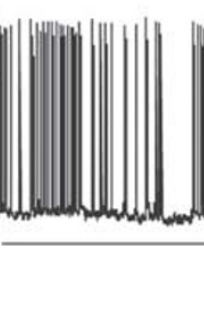

h

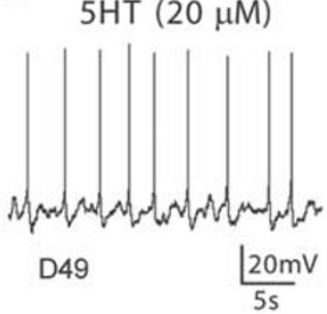

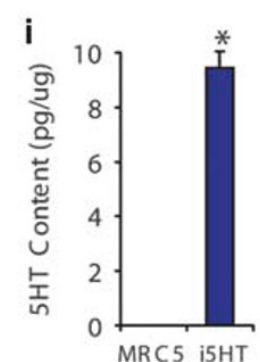

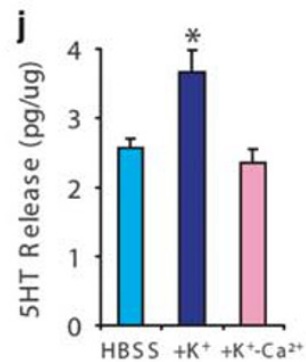

f

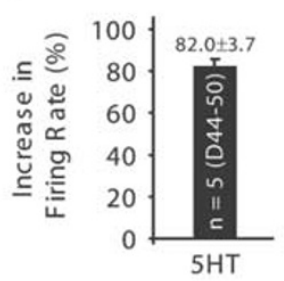

Figure 5. The i5HT neurons were functional. (a-d) Electrophysiological recordings showed that the i5HT neurons had voltage-gated $\mathrm{Na}^{+}$and $\mathrm{K}^{+}$currents (a), evoked action potentials in response to current injections (b), spontaneous action potentials (c) and spontaneous excitatory postsynaptic currents (d). (e-h) The frequency of spontaneous action potentials increased in response to serotonin (20 $\mu \mathrm{m})$ treatment, as shown in a representative recording (e), the statistical summary (f), and time-expanded segments of untreated (g) and treated (h) conditions. (i) Serotonin content in the i5HT neurons and the parental MRC5 fibroblasts. ${ }^{*} P<0.05, n=3$ independent experiments. (j) Serotonin released from i5HT neurons in Hank's balanced salt solution (HBSS), HBSS plus $\mathrm{KCl}(56 \mathrm{~mm})$, or $\mathrm{Ca}^{2+}$-free HBSS with $\mathrm{KCl}(56 \mathrm{~mm}) * P<0.05, \mathrm{vs}$ the other bars, $n=3$ independent experiments. (k) Serotonin uptake in the absent or present of the selective SERT inhibitor citalopram (10 $\mu \mathrm{m})$. ${ }^{*} P<0.05, n=3$ independent experiments.

This is consistent with many previous studies showing the difficulty in reprogramming adult cells than the fetal cells. ${ }^{29-31}$

\section{i5HT neurons have active synaptic transmission}

To test whether the i5HT neurons are functional, we performed electrophysiological recordings on neurons maintained for at least 46 days. Recordings at earlier time showed immature electrophysiological output (Supplementary Figure S7 and Supplementary Table 1). The i5HT neurons exhibited voltagedependent $\mathrm{Na}^{+}$and $\mathrm{K}^{+}$currents (Figure 5a), evoked action potentials (Figure 5b), spontaneous action potentials (Figure $5 \mathrm{c}$ ) and spontaneous excitatory postsynaptic currents (Figure $5 \mathrm{~d}$ ). More strikingly, the firing frequency of spontaneous action potentials was significantly increased by the application of $5 \mathrm{HT}$ $(20 \mu \mathrm{m})$ (Figures 5e-h), suggesting that these neurons have serotonin receptors that act to enhance neuronal excitability. Using HPLC coupled with electrochemical detection, ${ }^{15}$ we found that serotonin can be robustly detected in the i5HT neurons, but not the parental MRC5 fibroblasts (Figure 5i). Spontaneous 5HT release was measured by incubating the i5HT neurons in HBSS for $30 \mathrm{~min}$ (Figure 5j). Serotonin release was greatly increased in response to membrane depolarization induced by high concentration of $\mathrm{KCl}(56 \mathrm{~mm})$. This increase was completely blocked in $\mathrm{Ca}^{2+}$-free HBSS (Figure 5j). The i5HT neurons exhibited strong $5 \mathrm{HT}$ uptake, which was significantly blocked by the selective inhibitor of serotonin transporter, citalopram (10 $\mu \mathrm{m})$ (Figure 5k). Together, these results showed that the i5HT neurons have active serotonergic synaptic transmission.

\section{DISCUSSION}

Through a targeted screen based on existing knowledge on the development of serotonergic neurons in the mouse brain, we identified a combination of four transcription factors (AFLV) that converted primary human fibroblasts to induced serotonergic (i5HT) neurons in 12 days (Figure 1). The conversion efficiency and yield were significantly increased by p53 knockdown (Figure 1). Previous studies have demonstrated that the reprogramming of fibroblasts to iPS cells is significantly enhanced by attenuation of the p53 pathway. ${ }^{32-37}$ It is still unclear how p53 knockdown facilitate cellular reprogramming to pluripotency and to i5HT neurons in this case. Further studies are needed to understand the impact of p53 on reprogramming in general.

Consistent with previous studies that have shown the critical roles of Ascl1 in the transdifferentiation of fibroblasts to induced neurons, ${ }^{4}$ no neuron (including i5HT neuron) was generated in the absence of Ascl1 (Figure 1). When FoxA2 was not included, there was a dramatic reduction in the number of $5 \mathrm{HT}^{+}$neurons, whereas the number of Tuj $1^{+}$neurons was not significantly affected. This 
corroborates with the pivotal role of FoxA2 in specifying precursors of serotonergic neurons in the ventral hindbrain; deletion of FoxA2 in mice reduces hindbrain serotonergic neurons by $50 \%{ }^{8}$ Removing $L m \times 1 b$ from the reprogramming factors completely abrogated the production of i5HT neurons, without significantly affecting the production of $5 \mathrm{HT}^{-} / \mathrm{Tuj} 1^{+}$neurons, which accounted for approximately half of the neurons (Figure 1). This is consistent with the important role of $L m \times 1 b$ in the terminal differentiation of serotonergic neurons during development, as genetic ablation of $\mathrm{Lm \times 1b}$ in mice renders precursors of serotonergic neurons unable to turn on the battery of genes that specify serotonergic neurons. ${ }^{9,10}$ Although $\mathrm{Lm} \times 1 \mathrm{~b}$ and Pet1 (which is FEV in human) are both controlled by FoxA2 in the development of mouse serotonergic neurons, ${ }^{8}$ the omission of FEV in the reprogramming factors had a quite different effect compared with the removal of $L m \times 1 b$ (Figure 1). There was only a partial loss of $5 \mathrm{HT}^{+}$neurons in the absence of $\mathrm{FEV}$, but the number of Tuj $1^{+}$ neurons and the number of $\mathrm{DAPI}^{+}$cells increased significantly (Figure 1). It suggests that FEV is toxic, but facilitates the transdifferentiation of fibroblasts to i5HT neurons.

In screening for medium additives that can enhance the transdifferentiation, we found that the combination of ROCK inhibitor, double SMAD inhibitors dorsomorphin and SB431542, neurotrophic factors BDNF and GDNF, as well as the mitotic inhibitor PD0332991 markedly increased the efficiency (Figure 3j) and yield (Supplementary Figure S1b) of $5 \mathrm{HT}^{+}$neurons. The total number of Tuj $1^{+}$neurons was not significantly increased, but the significant decrease of DAPI ${ }^{+}$cells (by PD0332991) (Supplementary Figure S1d) markedly increased the apparent conversion efficiency for Tuj $1^{+}$neurons (Figure 3j). Other mitotic inhibitors, such as SU9516, AraA or AraC, had significant toxicity on i5HT neurons (Supplementary Figures S1q-t). Previous studies have shown that SB431542 $2^{38}$ and dorsomorphin ${ }^{39}$ enhance transdifferentiation of human fibroblasts to induced neurons. Although each of the media additives increased the efficiency in converting fibroblasts to i5HT neurons, the combined addition of all of them in induction media achieved a much bigger synergistic effect on reprogramming efficiency (Supplementary Figure S1a) and yield (Supplementary Figures S1b and c).

The i5HT neurons expressed appropriate markers for serotonergic neurons (Figure 4), exhibited active serotonergic synaptic transmission (Figures $5 \mathrm{e}$ and $\mathrm{f}$ ), and showed $\mathrm{Ca}^{2+}$-dependent release of serotonin (Figure $5 \mathrm{j}$ ) and selective uptake of serotonin (Figure 5k). The results show that the i5HT neurons possess characteristics very similar to serotonergic neurons in vivo. Thus, the method would be very useful for the generation of patientspecific serotonergic neurons for a variety of studies on many serotonin-related mental illnesses.

\section{CONFLICT OF INTEREST}

The authors declare no conflict of interest.

\section{ACKNOWLEDGMENTS}

The work was supported by National Key Basic Research Program of China grants 2011 CB504100 and 2011CB504104, National Natural Science Foundation of China grant 81430022, Department of Veterans Affairs Merit Award I01BX002452, NYSTEM contracts C028129, C029556 and C026714, and NIH grant NS061856.

\section{REFERENCES}

1 Ishimura K, Takeuchi Y, Fujiwara K, Tominaga M, Yoshioka H, Sawada T. Quantitative analysis of the distribution of serotonin-immunoreactive cell bodies in the mouse brain. Neurosci Lett 1988; 91: 265-270.

2 Muller CP, Jacobs B. Handbook of the Behavioral Neurobiology of Serotonin. Academic Press: Burlington, MA, USA, 2009.

3 Deneris ES, Wyler SC. Serotonergic transcriptional networks and potential importance to mental health. Nat Neurosci 2012; 15: 519-527.
4 Vierbuchen T, Wernig M. Molecular roadblocks for cellular reprogramming. Mol Cell 2012; 47: 827-838.

5 Castro DS, Guillemot F. Old and new functions of proneural factors revealed by the genome-wide characterization of their transcriptional targets. Cell Cycle 2011; 10: 4026-4031.

6 Wapinski OL, Vierbuchen T, Qu K, Lee QY, Chanda S, Fuentes DR et al. Hierarchical mechanisms for direct reprogramming of fibroblasts to neurons. Cell 2013; 155: 621-635.

7 Pattyn A, Simplicio N, van Doorninck JH, Goridis C, Guillemot F, Brunet JF et al. Ascl1/Mash1 is required for the development of central serotonergic neurons. Nat Neurosci 2004; 7: 589-595.

8 Jacob J, Ferri AL, Milton C, Prin F, Pla P, Lin W et al. Transcriptional repression coordinates the temporal switch from motor to serotonergic neurogenesis. Nat Neurosci 2007; 10: 1433-1439.

9 Cheng L, Chen CL, Luo P, Tan M, Qiu M, Johnson R et al. Lmx1b, Pet-1, and Nkx2.2 coordinately specify serotonergic neurotransmitter phenotype. J Neurosci 2003; 23: 9961-9967.

10 Ding YQ, Marklund U, Yuan W, Yin J, Wegman L, Ericson J et al. Lmx1b is essential for the development of serotonergic neurons. Nat Neurosci 2003; 6: 933-938.

11 Zhao ZQ, Scott M, Chiechio S, Wang JS, Renner KJ, Gereau RW 4th et al. Lmx1b is required for maintenance of central serotonergic neurons and mice lacking central serotonergic system exhibit normal locomotor activity. J Neurosci 2006; 26: 12781-12788.

12 Hendricks T, Francis N, Fyodorov D, Deneris ES. The ETS domain factor Pet- 1 is an early and precise marker of central serotonin neurons and interacts with a conserved element in serotonergic genes. J Neurosci 1999; 19: 10348-10356.

13 Pfaar H, von Holst A, Vogt Weisenhorn DM, Brodski C, Guimera J, Wurst W. mPet-1, a mouse ETS-domain transcription factor, is expressed in central serotonergic neurons. Dev Genes Evol 2002; 212: 43-46.

14 Hendricks TJ, Fyodorov DV, Wegman LJ, Lelutiu NB, Pehek EA, Yamamoto B et al. Pet-1 ETS gene plays a critical role in 5-HT neuron development and is required for normal anxiety-like and aggressive behavior. Neuron 2003; 37: 233-247.

15 Jiang H, Ren Y, Yuen EY, Zhong P, Ghaedi M, Hu Z et al. Parkin controls dopamine utilization in human midbrain dopaminergic neurons derived from induced pluripotent stem cells. Nat Commun 2012; 3: 668.

16 Kiyasova V, Gaspar P. Development of raphe serotonin neurons from specification to guidance. Eur J Neurosci 2011; 34: 1553-1562.

17 Wylie CJ, Hendricks TJ, Zhang B, Wang L, Lu P, Leahy P et al. Distinct transcriptomes define rostral and caudal serotonin neurons. J Neurosci 2010; 30: 670-684.

18 Pang ZP, Yang N, Vierbuchen T, Ostermeier A, Fuentes DR, Yang TQ et al. Induction of human neuronal cells by defined transcription factors. Nature 2011; 476: $220-223$.

19 Yoo AS, Sun AX, Li L, Shcheglovitov A, Portmann T, Li Y et al. MicroRNA-mediated conversion of human fibroblasts to neurons. Nature 2011; 476: 228-231.

20 Jensen P, Farago AF, Awatramani RB, Scott MM, Deneris ES, Dymecki SM. Redefining the serotonergic system by genetic lineage. Nat Neurosci 2008; 11: 417-419.

21 Flames N, Hobert O. Transcriptional control of the terminal fate of monoaminergic neurons. Annu Rev Neurosci 2011; 34: 153-184.

22 Watanabe K, Ueno M, Kamiya D, Nishiyama A, Matsumura M, Wataya T et al. A ROCK inhibitor permits survival of dissociated human embryonic stem cells. Nat Biotechnol 2007; 25: 681-686.

23 Kim DS, Lee JS, Leem JW, Huh YJ, Kim JY, Kim HS et al. Robust enhancement of neural differentiation from human ES and iPS cells regardless of their innate difference in differentiation propensity. Stem Cell Rev 2010; 6: 270-281.

24 Chambers SM, Fasano CA, Papapetrou EP, Tomishima M, Sadelain M, Studer L et al. Highly efficient neural conversion of human ES and iPS cells by dual inhibition of SMAD signaling. Nat Biotechnol 2009; 27: 275-280.

25 Fry DW, Harvey PJ, Keller PR, Elliott WL, Meade M, Trachet E et al. Specific inhibition of cyclin-dependent kinase $4 / 6$ by PD 0332991 and associated antitumor activity in human tumor xenografts. Mol Cancer Ther 2004; 3: 1427-1438.

26 Li W, Sun W, Zhang Y, Wei W, Ambasudhan R, Xia P et al. Rapid induction and longterm self-renewal of primitive neural precursors from human embryonic stem cells by small molecule inhibitors. Proc Natl Acad Sci USA 2011; 108: 8299-8304.

27 Sinha S, Chen JK. Purmorphamine activates the Hedgehog pathway by targeting Smoothened. Nat Chem Biol 2006; 2: 29-30.

28 Davila J, Chanda S, Ang CE, Sudhof TC, Wernig M. Acute reduction in oxygen tension enhances the induction of neurons from human fibroblasts. $J$ Neurosci Methods 2013; 216: 104-109.

29 Caiazzo M, Dell'Anno MT, Dvoretskova E, Lazarevic D, Taverna S, Leo D et al. Direct generation of functional dopaminergic neurons from mouse and human fibroblasts. Nature 2011; 476: 224-227.

30 Pfisterer U, Kirkeby A, Torper O, Wood J, Nelander J, Dufour A et al. Direct conversion of human fibroblasts to dopaminergic neurons. Proc Natl Acad Sci USA 2011; 108: 10343-10348. 
31 Kim J, Su SC, Wang H, Cheng AW, Cassady JP, Lodato MA et al. Functional integration of dopaminergic neurons directly converted from mouse fibroblasts. Cell Stem Cell 2011; 9: 413-419.

32 Zhao $Y$, Yin $X$, Qin $H$, Zhu $F$, Liu $H$, Yang $W$ et al. Two supporting factors greatly improve the efficiency of human iPSC generation. Cell Stem Cell 2008; 3: 475-479.

33 Kawamura T, Suzuki J, Wang YV, Menendez S, Morera LB, Raya A et al. Linking the p53 tumour suppressor pathway to somatic cell reprogramming. Nature 2009; 460: $1140-1144$

$34 \mathrm{Li} \mathrm{H}$, Collado M, Villasante A, Strati K, Ortega S, Cañamero M et al. The Ink4/Arf locus is a barrier for iPS cell reprogramming. Nature 2009; 460: 1136-1139.

35 Marion RM, Strati K, Li H, Murga M, Blanco R, Ortega S et al. A p53-mediated DNA damage response limits reprogramming to ensure iPS cell genomic integrity. Nature 2009; 460: 1149-1153.

36 Utikal J, Polo JM, Stadtfeld M, Maherali N, Kulalert W, Walsh RM et al. Immortalization eliminates a roadblock during cellular reprogramming into iPS cells. Nature 2009; 460: 1145-1148.
37 Hong H, Takahashi K, Ichisaka T, Aoi T, Kanagawa O, Nakagawa M et al. Suppression of induced pluripotent stem cell generation by the p53-p21 pathway. Nature 2009; 460: 1132-1135.

38 Ladewig J, Mertens J, Kesavan J, Doerr J, Poppe D, Glaue F et al. Small molecules enable highly efficient neuronal conversion of human fibroblasts. Nat Methods 2012; 9: 575-578.

39 Liu ML, Zang T, Zou Y, Chang JC, Gibson JR, Huber KM et al. Small molecules enable neurogenin 2 to efficiently convert human fibroblasts into cholinergic neurons. Nat Commun 2013; 4: 2183.

(c) (1) $(-)$ This work is licensed under a Creative Commons AttributionNonCommercial-NoDerivs 3.0 Unported License. The images or other third party material in this article are included in the article's Creative Commons license, unless indicated otherwise in the credit line; if the material is not included under the Creative Commons license, users will need to obtain permission from the license holder to reproduce the material. To view a copy of this license, visit http://creativecommons.org/licenses/by-nc-nd/3.0/

Supplementary Information accompanies the paper on the Molecular Psychiatry website (http://www.nature.com/mp) 